For: Perspective

\title{
Is habitat fragmentation good for biodiversity?
}

Robert J. Fletcher, Jr. a $^{\text {* }}$, Raphael K. Didham ${ }^{\mathrm{b}, \mathrm{c}}$, Cristina Banks-Leite ${ }^{\mathrm{d}}$, Jos Barlow ${ }^{\mathrm{e}}$, Robert M. Ewers $^{\mathrm{d}}$, James Rosindell ${ }^{\mathrm{d}}$, Robert D. Holt ${ }^{\mathrm{f}}$, Andrew Gonzalez ${ }^{\mathrm{g}}$, Renata Pardini ${ }^{\mathrm{h}}$, Ellen I.

Damschen $^{\mathrm{i}}$, Felipe P. L. Melo ${ }^{\mathrm{j}}$, Leslie Ries ${ }^{\mathrm{k}}$, Jayme A. Prevedello ${ }^{1}$, Teja Tscharntke ${ }^{\mathrm{m}}$, William F. Laurance $^{\mathrm{n}}$, Thomas Lovejoy ${ }^{\mathrm{o}}$, Nick M. Haddad ${ }^{\mathrm{p}}$

*Corresponding author: Department of Wildlife Ecology and Conservation, PO Box 110430, 110 Newins-Ziegler Hall, University of Florida, Gainesville, FL 32611-0430.

aDepartment of Wildlife Ecology and Conservation, PO Box 110430, 110 Newins-Ziegler Hall, University of Florida, Gainesville, FL 32611-0430.

${ }^{\mathrm{b}}$ School of Biological Sciences, The University of Western Australia, 35 Stirling Highway, Crawley WA 6009, Australia

${ }^{\mathrm{c} C S I R O}$ Land and Water, Centre for Environment and Life Sciences, 147 Underwood Ave, Floreat WA 6014, Australia

${ }^{\mathrm{d} D e p a r t m e n t ~ o f ~ L i f e ~ S c i e n c e s, ~ I m p e r i a l ~ C o l l e g e ~ L o n d o n, ~ S i l w o o d ~ P a r k ~ c a m p u s, ~}$ Buckhurst Road, Ascot, Berkshire, SL5 7PY, UK

${ }^{\mathrm{e}}$ Lancaster Environment Centre, Lancaster University, LA1 4YQ, UK

fDepartment of Biology, University of Florida, Gainesville, FL 32611-0430.

'Department of Biology, McGill University, Montreal, H3A 1B1, Qc, Canada

hDepartamento de Zoologia, Instituto de Biociências, Universidade de São Paulo, Rua do Matão, travessa 14, 101, CEP 05508-090, São Paulo, SP, Brasil

iDepartment of Zoology, University of Wisconsin, Madison, WI, USA

${ }^{j}$ Departamento do Botânica, Universidade Federal de Pernambuco, Rua Prof. Moraes Rego S/N, 50670-901, Recife-PE, Brasil

${ }^{\mathrm{k}}$ Department of Biology, Georgetown University

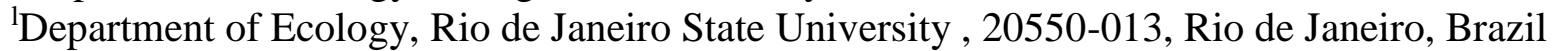

mAgroecology, Department of Crop Sciences, University of Göttingen, Göttingen, Germany

${ }^{\mathrm{n}}$ Centre for Tropical Environmental and Sustainability Science, and College of Science and Engineering, James Cook University, Cairns, Queensland, 4878, Australia

${ }^{\circ}$ Department of Environmental Science and Policy, George Mason University

${ }^{\mathrm{p}}$ Kellogg Biological Station, Department of Integrative Biology, Michigan State University 3700 E Gull Lake Dr, Hickory Corners, MI 49060

Running header: Responses to habitat fragmentation 


\section{Abstract}

2 Habitat loss is a primary threat to biodiversity across the planet, yet contentious debate has ensued on the importance of habitat fragmentation 'per se' (i.e., altered spatial configuration of

4 habitat for a given amount of habitat loss). Based on a review of landscape-scale investigations, Fahrig (2017; Ecological responses to habitat fragmentation per se. Annual Review of Ecology,

6 Evolution, and Systematics 48:1-23) reports that biodiversity responses to habitat fragmentation 'per se' are more often positive rather than negative and concludes that the widespread belief in

8 negative fragmentation effects is a 'zombie idea'. We show that Fahrig's conclusions are drawn from a narrow and potentially biased subset of available evidence, which ignore much of the

10 observational, experimental and theoretical evidence for negative effects of altered habitat configuration. We therefore argue that Fahrig's conclusions should be interpreted cautiously as

12 they could be misconstrued by policy makers and managers, and we provide six arguments why they should not be applied in conservation decision-making. Reconciling the scientific

14 disagreement, and informing conservation more effectively, will require research that goes beyond statistical and correlative approaches. This includes a more prudent use of data and conceptual models that appropriately partition direct vs indirect influences of habitat loss and altered spatial configuration, and more clearly discriminate the mechanisms underpinning any changes. Incorporating these issues will deliver greater mechanistic understanding and more predictive power to address the conservation issues arising from habitat loss and fragmentation. 


\section{Highlights}

- Habitat loss and fragmentation have long been considered to have negative effects on biodiversity, yet recent review by Fahrig (2017) argues that in fact habitat fragmentation has largely positive effects on biodiversity.

- We highlight several key short-comings to the approach taken in Fahrig (2017) that limits conclusions regarding habitat fragmentation effects.

- Several sources of counter evidence not considered in Fahrig (2017) illustrate that negative effects of habitat fragmentation are common and that positive effects can be misleading or not of conservation importance.

- We provide six key reasons why the conclusions in Fahrig (2017) should not be used in conservation decision-making.

Keywords: Habitat amount, habitat loss, configuration, biodiversity 


\section{Introduction}

36 Land-use change is impacting biodiversity across the planet (Newbold et al. 2015). There is no question that the extent and condition of native vegetation has declined precipitously in recent decades, such that most species now live in fragmented patches of degraded habitat, subject to rising threats from the surrounding anthropogenic matrix (Haddad et al. 2015; Pfeifer et al.

40 2017). Conservation threat assessments in fragmented landscapes repeatedly emphasize that there are multiple causal agents of biodiversity decline that operate in complex and often

42 synergistic ways (e.g., Cote et al. 2016; Laurance and Useche 2009).

It is surprising, then, that claims have been made that habitat loss, and not the

44 configuration of remaining habitat, is sufficient to explain effects of land clearing on biodiversity loss, whereas the effects of habitat fragmentation (i.e., altered spatial configuration of habitat for

46 a given amount of habitat loss) are often 'weak' or 'absent' (Fahrig 2003, p. 508). The argument is that the effects of habitat loss are overwhelming and that the complexity of effects due to

48 habitat fragmentation, such as declining patch areas, reductions in connectivity, or increasing edge effects, are not needed to explain patterns of biodiversity change in most landscapes. These

50 claims have had a major impact in focusing efforts on understanding the effects of habitat loss relative to habitat fragmentation (see summary in Hadley and Betts 2016), and it is clear that

52 habitat loss has severe effects on biodiversity (e.g., Brooks et al. 2002; Schipper et al. 2008), as emphasized in Fahrig (2003). However, a large body of evidence runs counter to claims that

54 habitat fragmentation effects are weak or absent. Not only have the pattern and process of habitat fragmentation been shown to have substantial and lasting effects on biodiversity (e.g., Haddad et al. 2015), but also the spatial configuration of habitat loss has been shown to influence how habitat loss effects extend into remaining habitat (Barlow et al. 2016; Pfeifer et al. 2017). 
The viewpoint that fragmentation is not important has arisen primarily because statistical models that attempt to partition 'independent' effects of habitat loss from habitat fragmentation tend to show greater effects of habitat loss (Fahrig 2003). These models would be valid if the processes of habitat loss and fragmentation were conceptually and empirically independent, and

62 the resulting spatial patterns of habitat amount and configuration could be treated as statistically independent (Koper et al. 2007; Smith et al. 2009). However, others have argued that habitat loss and fragmentation are frequently linked, such that statistical independence of the resulting patterns must be explicitly tested rather than assumed (Didham et al. 2012). In fact, landscapes

66 across most regions of the world exhibit very high collinearity between habitat amount and configuration (e.g., Cushman et al. 2008; Liu et al. 2016). Because of these real-world patterns,

68 Ruffell et al. (2016) argue that the causal basis of this collinearity should be incorporated explicitly into statistical models, most logically by partitioning the direct vs indirect mechanisms by which habitat loss influences ecological responses via the mediating effects of altered habitat configuration.

Even though there is apparent disparity in philosophical and analytical perspectives, it is important to point out that both perspectives share a fundamental motivation for discriminating

74 the effects of habitat amount and configuration: to allow more targeted and cost-effective use of scarce conservation resources on the factor(s) of greatest importance for biodiversity loss (Fahrig 2003; Ruffell et al. 2016). After all, conservation strategies may well differ in their effectiveness when focusing on mitigating habitat loss versus changes in habitat configuration (Villard and

78 Metzger 2014). The 'loss versus fragmentation' question has consequently become a major focus of research within landscape ecology and conservation (Hadley and Betts 2016). 
Now, however, Fahrig (2017) has made a new claim in a review of studies that attempt to separate the effects of habitat fragmentation 'per se' from habitat loss. Fahrig concludes that the

82 weight of evidence supports largely positive effects of habitat fragmentation 'per se' on biodiversity, and that the negative effect of habitat fragmentation on biodiversity is a "zombie 84 idea" - a concept that is repeatedly refuted but yet somehow survives (Quiggen 2010). Fahrig then casts a wide net for other so-called 'zombie' ideas: large patches contain more species than several small patches of similar combined area, edge effects are typically negative, habitat fragmentation reduces connectivity, habitat specialists have stronger negative responses to habitat fragmentation relative to generalists, and negative effects of habitat fragmentation are stronger in the tropics and at low levels of habitat amount (Table 1). counter to mainstream empirical and theoretical research on diverse components of habitat

92 configuration effects (e.g., Haddad et al. 2015; Tilman and Lehman 1997), suggesting the ecological research community has been mired in consensus and blind to the positive effects of

94 habitat fragmentation. Second, they have major implications for the management of the world's fragmented ecosystems.

Given the importance of these issues, we re-evaluate Fahrig's assessment. First, we discuss why the review process utilized by Fahrig likely biased the findings and led to unwarranted conclusions. Second, we address the origins of the conflicting viewpoints, illustrating that there is ample empirical evidence and theory that laid the foundation for the idea of negative effects of habitat fragmentation that were not acknowledged in Fahrig (2017) (see Table 1 for a non-exhaustive list of summaries). Third, we discuss why these conclusions should not be applied to conservation in fragmented landscapes. We conclude by highlighting areas of 
consensus to help advance the conceptual understanding and applied relevance of habitat 104 fragmentation effects.

\section{The review and conclusions on fragmentation effects}

Over the past two decades, several reviews and meta-analyses have suggested that the effects of different spatial components of habitat fragmentation, such as habitat edge or isolation, have undesirable or variable effects on ecological responses (Debinski and Holt 2000; Ewers and Didham 2006; Fletcher et al. 2016; Fletcher et al. 2007; Gilbert-Norton et al. 2010; Haddad et al. 2015; Pfeifer et al. 2017; Ries et al. 2004; Ries et al. 2017). Yet in some of these reviews there

112 have not been attempts to discriminate the relative effects of altered spatial configuration (Fahrig's 'habitat fragmentation per se') from habitat loss.

Fahrig (2017) attempted to fill this important gap by conducting "a complete search for studies documenting statistically significant responses to habitat fragmentation" (p.6). Fahrig screened over 5000 articles, but just 118 of these (381 significant responses) met nine criteria used for inclusion. Notable criteria included the sole use of landscape-scale studies (where the landscape location and size were defined by the investigator), such that patch-scale studies were ignored. Habitat fragmentation was separated from habitat loss in one of three ways: through experimental manipulations of landscapes, through statistical analysis aimed at partialling out variation due to habitat amount, and through the use of what Fahrig refers to as 'SLOSS' designs

122 (where variation in species richness between Single Large or Several Small patches is compared using species accumulation curves as a function of habitat amount in the landscape; Quinn and

124 Harrison 1988). Fahrig also included only those studies that could be summarized as habitat fragmentation having simple positive or negative effects, while non-linear effects (e.g., hump- 
126 shaped relationships) and other complex effects (e.g., changes in community composition, scaledependent effects) were not included. Inference was taken from what the authors of the original

128 studies reported as 'significant' rather than using a formal meta-analysis, and all conclusions were based on responses reported rather than summaries of studies (i.e., the response variable in an

130 individual study was the independent sampling unit). Results were only taken from tables and figures; the main text was ignored.

Fahrig found that $76 \%$ of the significant fragmentation effects used in the review were positive. In this context, 'positive effects' refer to situations where response variables (e.g.,

134 abundance, richness, movement success) increase with increasing values of habitat fragmentation metrics (e.g., number of patches, mean patch size, edge density and so on). Fahrig (2017, p. 18)

136 then concluded that the widespread notion that habitat fragmentation generally has negative effects is a 'zombie idea' and several other conservation-focused conclusions (Table 1), such as

138 the conservation value of small patches should not be lower than for an equivalent area within a large patch.

\section{Are these conclusions warranted?}

142 The results in Fahrig (2017) were surprising, yet the review's main conclusions come from a narrow subset of literature and do not provide reliable evidence or sufficient context to dismiss

144 the negative effects of fragmentationas a 'zombie' idea. We focus on three key reasons why this is the case: 1) the search terms and review criteria led to the omission of key literature; 2) the use 146 of a vote-counting approach likely biased the relative weighting of findings; and 3) there has been no evidence of repeated, widespread refutation of negative habitat fragmentation effects in 148 the literature prior to Fahrig's review. 
First, the search terms and review criteria used by Fahrig (2017) led to the omission of a 150 large body of relevant literature on habitat fragmentation effects. The only search term used to explicitly capture habitat fragmentation was "fragmentation per se", rather than a more general 152 term such as "fragmentation" or a wild-card search on "fragment*". Based on a Web of Science search on 18 April 2018, the number of hits using Fahrig's search phrase was 1,926, whereas the 154 same search with "fragmentation" yielded 141,148 hits, and "fragment*" yielded 525,066 hits. Clearly, not all of these latter hits reflect investigations on habitat fragmentation, but focusing 156 just on "fragmentation per se", a phrase popularized by Fahrig (2003), greatly narrowed the scope of articles considered and likely led to a biased selection of articles on fragmentation and its effects. As a consequence, some rigorous, landscape-scale experiments that show striking negative effects of fragmentation were missed (e.g., Gonzalez et al. 1998). Moreover, Fahrig only considered landscape-scale investigations. Such investigations are useful but not sufficient for interpreting habitat fragmentation effects, because there are many rigorous patch-scale 162 investigations that are highly relevant to the questions addressed. For instance, the Savannah River Corridor Experiment provides a large-scale, long-term, patch-focused experiment in which 164 patches are either connected with corridors (less fragmented) or not (more fragmented), while overall habitat amount is controlled (Haddad et al. 2017). Based on an analysis of 171 response 166 variables (from 41 articles) using the same vote counting approach as described in Fahrig (2017; note this approach has limitations-see below), corridors had 4.7 times more positive effects than 168 negative effects, providing strong experimental evidence for negative effects of at least one component of habitat fragmentation (Haddad et al. 2015). A meta-analysis of larger-scale 170 observational studies on corridors found very similar effects (Gilbert-Norton et al. 2010). None of this work was included in the review (see Appendix in Fahrig 2017). The inclusion of this one 
172 experiment would have nearly doubled the number of negative responses reported $(n=91)$, potentially leading to different conclusions.

The criteria also favored particular study designs that provide relatively weak inference in their ability to detect habitat fragmentation effects. Most of the investigations $(72 \% ; 273$ of 381

176 responses) come from observational studies that used statistical techniques that first partition out all variance associated with habitat loss, and then interpret habitat fragmentation as the residual

178 variance left in the model. However, the more fragmented the landscape, the larger the spatial extent that is sampled from a previously contiguous landscape in observational studies (e.g., see

180 Figures 1, 2, 4 and 5 in Fahrig 2017), such that trends for a greater number of species with increasing habitat fragmentation may be inherently confounded with the greater spatial extent of

182 the area sampled. Increasing spatial extent is problematic for comparisons because of Tobler's First Law of Geography (Tobler 1970), which emphasizes that environmental conditions at close 184 locations are more similar than conditions farther away such that an increasing extent will no doubt capture greater environmental heterogeneity irrespective of habitat loss and fragmentation 186 effects. Furthermore, these statistical techniques have been repeatedly shown to be limited in their ability to discriminate habitat fragmentation effects and implicitly attribute most of the 188 intercorrelated variance to effects of habitat loss (Koper et al. 2007; Ruffell et al. 2016; Smith et al. 2009). Such a bias in the statistical methods being used to test for 'independent' effects may 190 reflect the starting assumptions of the authors rather than processes impacting biodiversity.

A related limitation regarding the criteria for analysis and interpretation of data was the 192 use of SLOSS analyses, where species accumulation curves are compared when ranking patches from small-to-large and from large-to-small patches. These curves are then typically summarized 194 with a 'saturation index' that reflects whether species number tends to be greater with habitat 
subdivision for a given amount of habitat (Quinn and Harrison 1988). With this approach, Fahrig

196 found all 60 investigations had more rapid species accumulation when ranking from small-tolarge, a rather striking pattern that suggests a positive effect of fragmentation (Table 1).

198 However, this approach has been criticized for several fundamental reasons. First, it does not provide a measure of 'significance' (Mac Nally and Lake 1999), despite Fahrig stating that the

200 review only included 'significant' responses. Second, and more importantly, this general approach has been shown to lead to bias in favor of several small reserves in a variety of

202 situations (Ramsey 1989). For example, Mac Nally and Lake (1999) used mechanistic models for species occurrence under scenarios of greater species accumulation in several small versus 204 single large patches. They illustrate how conclusions based on species accumulation curves, like that used by Fahrig, tend to conclude positive effects of fragmentation even when mechanistic models simulating preference of the community for larger patches fit empirical data better than assuming preference for small patches. Mac Nally and Lake (1999) conclude, "it [small-to-large vs large-to-small ranking] is a deeply flawed technique that provides spurious implications about the nature of diversity generation in archipelagos and systems of patches...SL [Single-large]-

210 dominance probably is common and that it cannot be easily detected by using the simple graphical methods of Quinn and Harrison".

Second, vote counting approaches have well-known limitations in drawing inference across studies due to bias generation, low statistical power, and inability to provide relevant 214 information to appropriately summarize results from a set of studies (Gurevitch et al. 2018; Koricheva et al. 2013). Fahrig's results were based on simple counts of 'statistically significant' 216 responses, rather than estimated effect sizes that acknowledge effect magnitude and sample size, such that variation in study design is ignored. As a consequence, a study including few 
218 landscapes but many measured response variables had more weight in the review than a study with a more robust sampling design that included many landscapes but that focused on few 220 response variables. For example, two articles highlighted in Fahrig (2017) include Radford and Bennett (2007), who reported 19 significant responses using 24 landscapes, and Smith et al.

222 (2011), who reported 3 significant responses with 2951 landscapes. In this case, Radford and Bennett (2007) had the potential to provide $6 \times$ more weight in conclusions, despite having $<1 \%$ 224 of the sample size of Smith et al. (2011).

Third, even if the search terms and inclusion criteria were valid, the finding of a mix of 226 positive and negative responses to habitat fragmentation does not satisfy the criterion for a 'zombie' idea - that the concept has been repeatedly refuted over time and yet lives on (Quiggen

228 2010). The conclusion drawn by Fahrig (2017) that positive fragmentation effects are more common than negative effects represents a new claim; there have not been repeated prior 230 syntheses making similar claims sufficient to suggest that this is a 'zombie' idea. Even Fahrig's compilation suggests $24 \%$ of responses are negative, illustrating that negative effects based on

232 the review criteria are not uncommon. Importantly, Fahrig does not provide any explicit data or evidence to support several other related 'zombie' ideas (Table 1), such as those on edge effects 234 or connectivity, and these assertions are in stark contrast to the decades of empirical evidence on these topics (Haddad et al. 2015; Ries et al. 2004). For example, Fahrig argues that the idea that 236 edge effects are typically negative is false, without providing any data to support this argument, while Pfeifer et al. (2017) clearly illustrate from data collected across the planet that edge effects 238 are highly variable and that species of greatest conservation concern tend to be negatively affected by habitat edge. 
Finally, we emphasize that key responses to fragmentation can be missed in studies of short duration, such as many of those reviewed in Fahrig (2017). Unlike habitat amount, habitat

242 loss and fragmentation explicitly capture temporal processes - habitat is lost and fragmented over time. Yet, investigators often use space-for-time substitution, focusing on the pattern of

244 habitat to infer how loss and fragmentation impact biodiversity. Temporal effects from environmental change can arise for a variety of reasons, such as time lags in impacts and extinction debts (Hylander and Ehrlen 2013; Jackson and Sax 2010). For example, many of the effects that arise from the creation of habitat edges require time to manifest, such as changes in vegetation structure arising from tree mortality that frequently occurs near edges (Laurance et al. 2006). Long-term experiments and observational studies have shown delayed effects of

250 fragmentation on biodiversity over time (e.g., Haddad et al. 2015). Consequently, current habitat amount and configuration, as emphasized in Fahrig (2017), may not be a good predictor of

252 ongoing effects of habitat loss and fragmentation. Temporal effects of fragmentation have a strong theoretical and empirical basis and should be assessed when possible (Haila 2002).

\section{Origins of conflicting viewpoints}

256 Fahrig (2017) argues several reasons why most other researchers erroneously believe that habitat fragmentation has negative effects. One point Fahrig raises $(\mathrm{p} .2,18)$ is that early conceptual

258 work relevant to habitat fragmentation confounded habitat patchiness with habitat amount (e.g., den Boer 1968; MacArthur and Wilson 1967). Decades of advances in metapopulation and

260 metacommunity theory show clearly that effects of habitat fragmentation can increase extinction rates and decrease colonization rates, leading to reduced likelihood of population persistence and 262 lower diversity (e.g., Adler and Nuernberger 1994; Hill and Caswell 1999; Thompson et al. 
2017; Tilman and Lehman 1997). In some cases, positive effects of habitat fragmentation at the

264 community level are predicted to arise from increases in beta-diversity driven by different resource requirements of species and the fact that more fragmented habitats typically encompass

266 a greater spatial extent and environmental heterogeneity (Chisholm et al. 2018; Lasky and Keitt 2013; Rosch et al. 2015). Yet, even in such situations, models predict that this positive effect is

268 expected to reverse when habitat amount reaches low levels (Rybicki and Hanski 2013). Much of this large body of theory emphasizes that habitat fragmentation is often predicted to have

270 negative effects on biodiversity, over and above declining habitat amount.

A second point that Fahrig emphasizes is that there has been inappropriate extrapolation

272 of patch-scale patterns to landscape-scale inferences. Fahrig argues that fragmentation effects must be tested at the landscape-scale. The rationale for dismissing patch-scale effects appears to

274 be three-fold. First, Fahrig (Fahrig 2003, 2017) argues that habitat fragmentation is a landscapescale phenomenon, and therefore patch-scale studies are not relevant. While habitat

276 fragmentation often (but not always) occurs at landscape scales, the mechanisms of biodiversity responses can in fact occur from patch-scale changes, such as edge effects, changes in behavior

278 of organisms, or local species interactions (Banks-Leite et al. 2010; Fletcher 2006; Hadley et al. 2014). Consequently, patch-scale studies can provide critical insight to the mechanisms by which

280 habitat fragmentation influence biodiversity. Second, patch isolation metrics are frequently correlated with habitat amount in the surrounding landscape, so Fahrig argues that the habitat 282 amount explanation takes primacy and therefore isolation effects are actually habitat amount effects. Third, patch size effects are dismissed as habitat amount effects because "smaller patches

284 have less habitat than larger patches" (p.3). These arguments imply that any arbitrary spatial scale can be used to define a 'landscape', allowing the primacy of habitat amount in the 
286 'landscape' to be invoked over patch-scale effects. Both of these lines of reasoning are problematic for paring down either the effects of habitat loss or spatial configuration to their root mechanistic causes (Didham et al. 2012), and ignore the fact that patch metrics are not only correlated with habitat amount but are also highly cross-correlated with aspects of habitat spatial configuration (Cushman et al. 2008).

Arguably, since Fahrig $(2013,2017)$ argues 'habitat amount' is a primary predictor of

292 biodiversity change in response to land clearing and habitat fragmentation effects are rare, then it should be possible to infer that the underlying mechanism(s) relate directly to habitat availability 294 in the landscape, and not to potential dispersal limitation of organisms, or their ability to survive in a local patch once they arrive. To explain the habitat amount effect, Fahrig (2013) focuses 296 entirely on a neutral 'sample area effect' (Haddad et al. 2017). Yet at their core, isolation effects are relevant to habitat fragmentation through the disruption of successful dispersal. Both habitat 298 configuration and spatial characteristics of the matrix have been shown repeatedly to be critical for movement, dispersal, and gene flow (e.g., Cushman et al. 2012; Fletcher et al. 2014;

300 Gonzalez et al. 1998; Ricketts 2001), such that empirical research on movement does not mechanistically support the idea that isolation effects are solely habitat amount effects. Even if

302 habitat amount can statistically explain responses without explicit inclusion of measures of fragmentation, such conclusions are misleading if a key part of the true underlying mechanistic

304 pathway for their effects is via augmenting connectivity and dispersal. In addition, simply reducing patch-size effects to habitat amount effects is inconsistent with decades of research on 306 edge and patch-size effects, where there is incontestable evidence that habitat suitability can vary spatially within patches in relation to configuration variables, such as distance from edge. Edge 308 effects can be positive or negative (Pfeifer et al. 2017), and can drive emergent patch-level 
outcomes (Banks-Leite et al. 2010; Ewers et al. 2007), particularly where multiple edges interact

310 in increasingly small fragments (Fletcher 2005). There can also be complex and unpredictable ecological outcomes that emerge in small isolated fragments through random trajectories of

312 change in species interaction networks, and it is challenging to see how 'habitat amount in the landscape' could be mechanistically linked to these kinds of effects. In the absence of alternative

314 mechanisms suggested by Fahrig (2017), we argue that mechanistic understanding requires acknowledging that both habitat amount and configuration operate across spatial scales from

316 local- to patch- to landscape-scales (Didham et al. 2012; Pardini et al. 2010).

\section{5. Implications for management and conservation in the real world}

We believe that the overall goal for most science on habitat fragmentation is to gain a deeper mechanistic understanding of why habitat configuration effects occur, how they might mediate the relationship between habitat loss and biodiversity decline, and ways to mitigate the impacts

322 of habitat loss and related land-use change (e.g., via conservation corridors). Ignoring or diminishing the importance of spatial configuration effects as a core part of that mechanistic

324 understanding comes with significant risks for landscape management and conservation. Here we briefly outline six reasons why Fahrig's (2017) conclusions on the effects of habitat

326 fragmentation should not be used to guide management.

First, Fahrig argues that conservation biologists have falsely emphasized habitat

328 fragmentation over habitat loss as the most significant cause of biodiversity decline, when in fact only habitat loss has substantive effects. However, this conclusion only arises because of the implicit assumption that multiple predictors can be treated as 'independent' for conservation, when in fact changes in habitat amount and configuration through time are almost always 
332 collinear in real-world landscapes where conservation decision-makers are charged with making real-world choices (Didham et al. 2012; Villard and Metzger 2014).

Second, Fahrig emphasizes that more fragmented habitats have proportionally more edge, and that conclusions for these largely positive effects of habitat fragmentation were often attributed to edge effects. Edges can indeed have positive or negative effects on species (Pfeifer et al. 2017; Ries et al. 2004); however, positive edge effects most commonly have several practical (and frequently negative) consequences for conservation and management. Species associated with edges are often generalists or invasive (Banks-Leite et al. 2010; Pfeifer et al. 340 2017). Increased edge in fragmented landscapes can also increase risk from a suite of negative pressures, such as livestock incursion, wildfire, logging, and human-wildlife conflict (e.g.,

342 Echeverria et al. 2007; Goswami et al. 2014), and it can also facilitate further habitat loss (Laurance et al. 2009).

Third, approximately one quarter $(24.4 \%)$ of Fahrig's results focused on species richness, with little consideration of species identity. Species richness is useful for summarizing ecological 346 patterns but can mask compositional changes that are highly relevant to conservation. For example, Fahrig (2017) included results from Blake and Karr (1984) as a positive response to 348 fragmentation, where more bird species were found in several small relative to single large fragments. However, Blake and Karr (1984) emphasized that richness of two groups of major conservation concern (long-distance migrants and forest interior species) decreased with fragmentation, two negative responses that were not included in Fahrig's summary (see also 352 Alstad et al. 2016; Banks-Leite et al. 2012).

Fourth, Fahrig suggests that the review conclusions may contribute to the land sharing vs 354 sparing debate in applied landscape management (Fischer et al. 2014), by supporting 
conservation of dispersed networks of several small fragments (assumed to reflect land-sharing)

356 over a single large block of forest (assumed to reflect land-sparing). This conclusion is

unwarranted, given that the land sharing/sparing debate emphasizes production yields and socio-

358 ecological interactions as integral components to these issues in the real world (Fischer et al. 2014), neither of which are included when considering habitat loss and fragmentation effects

360 alone.

Fifth, the review had a narrow focus on a habitat vs non-habitat dichotomy, assuming the

362 functionally-relevant habitat was appropriately measured and of comparatively similar quality across the landscape for the responses considered. For many species, the non-habitat matrix may

364 also provide resources and generic habitat delineation can obscure variation in habitat fragmentation effects (Betts et al. 2014). Landscapes can thus be classified as more fragmented 366 even though they may actually be less fragmented from a species' perspective. For instance, many positive edge responses can be explained by putative 'non-habitat' actually providing resources to species (Ries et al. 2004). As such, positive effects of habitat fragmentation are expected for species that are not specialized in the given habitat type-species that are often not 370 of conservation concern.

Sixth, and perhaps most importantly for decision-makers, Fahrig (2017) tends to 372 erroneously conflate statistical and ecological conclusions. Throughout most of the review, Fahrig focuses on the statistical direction of response being either positive or negative. This

374 should not be confused with a 'positive outcome' in a qualitative sense from a conservation perspective, where some positive effects, such as an increase in the number of exotic species 376 with habitat fragmentation, would be considered a 'negative outcome' for conservation. Given Fahrig does briefly acknowledge this issue, it is alarming that the review concludes that (p.19), 
378 "there is no justification for assigning lower conservation value to small patches than to an equivalent area within a large patch—instead, it implies just the opposite".

\section{Conclusions and moving forward}

382 We agree with Fahrig that habitat loss is well known to have large negative effects on biodiversity, and that small fragments can have conservation value for biodiversity and

384 ecosystem services (e.g., Mitchell et al. 2014). We also agree that the term 'habitat fragmentation' is often used interchangeably as both a loose catch-phrase to refer to the overall process of changing amount and configuration of habitat through time, and as a more refined characterization of altered spatial configuration in the landscape (as we have attempted to do here). Semantic issues aside, we agree that habitat fragmentation (in the broad or strict sense) can sometimes lead to statistical increases in ecological response variables, particularly in multispecies responses where different members of the community may be using different resources across heterogeneous landscapes, leading to greater beta-diversity in more fragmented landscapes. None of these factors are in dispute, nor have they been in dispute for many years prior to Fahrig's review (e.g., see syntheses by Debinski and Holt 2000; Ewers and Didham 394 2006; Tscharntke et al. 2012).

Fahrig's review provides insufficient evidence for the conclusion that habitat fragmentation effects are largely positive. Such a conclusion is only possible with an unreasonable set of assumptions that narrows the evidence base. We caution that fueling 398 polarized perspectives with invective can stymie research growth, and could have unintended and unjustified ramifications for conservation and management. The take-home message should be a call to all scientists working at the forefront of issues on habitat loss and fragmentation to 
more clearly discriminate the mechanisms via which they impact biodiversity and to consider mechanistic modeling in addition to the statistical and correlative approaches that have fueled the present disagreements. Understanding why and when these habitat fragmentation effects occur,

404 how they interact with other human-induced changes, and under what situations fragmentation effects will be positive or negative will be essential for conserving biodiversity.

\section{Acknowledgements}

This research was supported by the National Science Foundation (DEB-1655555 to RF and RH).

AG is supported by the Liber Ero chair in Biodiversity Conservation. RP is supported by a

Tecnológico) - 308205/2014-6.

\section{Competing Interests}

414 The authors declare no competing interests.

\section{References}

Adler, F.R., Nuernberger, B., 1994. Persistence in patchy irregular landscapes. Theoretical 418 Population Biology 45, 41-75.

Alstad, A.O., Damschen, E.I., Givnish, T.J., Harrington, J.A., Leach, M.K., Rogers, D.A., 420 Waller, D.M., 2016. The pace of plant community change is accelerating in remnant prairies.

Science Advances 2. 
422 Banks-Leite, C., Ewers, R.M., Metzger, J.P., 2010. Edge effects as the principal cause of area effects on birds in fragmented secondary forest. Oikos 119, 918-926.

424 Banks-Leite, C., Ewers, R.M., Metzger, J.P., 2012. Unraveling the drivers of community dissimilarity and species extinction in fragmented landscapes. Ecology 93, 2560-2569.

426 Barlow, J., Lennox, G.D., Ferreira, J., Berenguer, E., Lees, A.C., Mac Nally, R., Thomson, J.R., Ferraz, S.F.D., Louzada, J., Oliveira, V.H.F., Parry, L., Solar, R.R.D., Vieira, I.C.G., Aragao, L., 428 Begotti, R.A., Braga, R.F., Cardoso, T.M., de Oliveira, R.C., Souza, C.M., Moura, N.G., Nunes, S.S., Siqueira, J.V., Pardini, R., Silveira, J.M., Vaz-de-Mello, F.Z., Veiga, R.C.S., Venturieri, A., 430 Gardner, T.A., 2016. Anthropogenic disturbance in tropical forests can double biodiversity loss from deforestation. Nature 535, 144-+.

432 Betts, M.G., Fahrig, L., Hadley, A.S., Halstead, K.E., Bowman, J., Robinson, W.D., Wiens, J.A., Lindenmayer, D.B., 2014. A species-centered approach for uncovering generalities in organism 434 responses to habitat loss and fragmentation. Ecography 37, 517-527.

Blake, J.G., Karr, J.R., 1984. Species composition of bird communiteis and the conservation 436 benefit of large versus small forests. Biological Conservation 30, 173-187.

Brooks, T.M., Mittermeier, R.A., Mittermeier, C.G., da Fonseca, G.A.B., Rylands, A.B., 438 Konstant, W.R., Flick, P., Pilgrim, J., Oldfield, S., Magin, G., Hilton-Taylor, C., 2002. Habitat loss and extinction in the hotspots of biodiversity. Conservation Biology 16, 909-923.

440 Chisholm, R.A., Lim, F., Yeoh, Y.S., Seah, W.W., Condit, R., Rosindell, J., 2018. Species-area relationships and biodiversity loss in fragmented landscapes. Ecology Letters 21, 804-813.

442 Cote, I.M., Darling, E.S., Brown, C.J., 2016. Interactions among ecosystem stressors and their importance in conservation. Proceedings of the Royal Society B-Biological Sciences 283. 
444 Cushman, S.A., McGarigal, K., Neel, M.C., 2008. Parsimony in landscape metrics: Strength, universality, and consistency. Ecological Indicators 8, 691-703.

446 Cushman, S.A., Shirk, A., Landguth, E.L., 2012. Separating the effects of habitat area, fragmentation and matrix resistance on genetic differentiation in complex landscapes. Landscape 448 Ecology 27, 369-380.

Debinski, D.M., Holt, R.D., 2000. A survey and overview of habitat fragmentation experiments. 450 Conservation Biology 14, 342-355.

den Boer, P.J., 1968. Spreading of risk and stabilization of animal numbers. Acta Biotheoretica 452 18, 165-194.

Didham, R.K., Kapos, V., Ewers, R.M., 2012. Rethinking the conceptual foundations of habitat 454 fragmentation research. Oikos 121, 161-170.

Echeverria, C., Newton, A.C., Lara, A., Benayas, J.M.R., Coomes, D.A., 2007. Impacts of forest 456 fragmentation on species composition and forest structure in the temperate landscape of southern Chile. Global Ecology and Biogeography 16, 426-439.

458 Ewers, R.M., Didham, R.K., 2006. Confounding factors in the detection of species responses to habitat fragmentation. Biological Reviews 81, 117-142.

460 Ewers, R.M., Thorpe, S., Didham, R.K., 2007. Synergistic interactions between edge and area effects in a heavily fragmented landscape. Ecology 88, 96-106.

462 Fahrig, L., 2003. Effects of habitat fragmentation on biodiversity. Annual Review of Ecology Evolution and Systematics 34, 487-515.

464 Fahrig, L., 2013. Rethinking patch size and isolation effects: the habitat amount hypothesis. Journal of Biogeography 40, 1649-1663. 
466 Fahrig, L., 2017. Ecological responses to habitat fragmentation per se. Annual Review of Ecology, Evolution, and Systematics 48, 1-23.

468 Fischer, J., Abson, D.J., Butsic, V., Chappell, M.J., Ekroos, J., Hanspach, J., Kuemmerle, T., Smith, H.G., von Wehrden, H., 2014. Land Sparing Versus Land Sharing: Moving Forward. 470 Conservation Letters 7, 149-157.

Fletcher, R.J., Jr., 2005. Multiple edge effects and their implications in fragmented landscapes.

472 Journal of Animal Ecology 74, 342-352.

Fletcher, R.J., Jr., 2006. Emergent properties of conspecific attraction in fragmented landscapes.

474 American Naturalist 168, 207-219.

Fletcher, R.J., Jr., Acevedo, M.A., Robertson, E.P., 2014. The matrix alters the role of path 476 redundancy on patch colonization rates. Ecology 95, 1444-1450.

Fletcher, R.J., Jr., Burrell, N., Reichert, B.E., Vasudev, D., 2016. Divergent perspectives on

478 landscape connectivity reveal consistent effects from genes to communities. Current Landscape Ecology Reports 1, 67-79.

480 Fletcher, R.J., Jr., Ries, L., Battin, J., Chalfoun, A.D., 2007. The role of habitat area and edge in fragmented landscapes: definitively distinct or inevitably intertwined? Canadian Journal of 482 Zoology 85, 1017-1030.

Gilbert-Norton, L., Wilson, R., Stevens, J.R., Beard, K.H., 2010. A Meta-Analytic Review of 484 Corridor Effectiveness. Conservation Biology 24, 660-668.

Gonzalez, A., Lawton, J.H., Gilbert, F.S., Blackburn, T.M., Evans-Freke, I., 1998.

486 Metapopulation dynamics, abundance, and distribution in a microecosystem. Science 281, 20452047. 
488 Goswami, V.R., Vasudev, D., Oli, M.K., 2014. The importance of conflict-induced mortality for conservation planning in areas of human-elephant co-occurrence. Biological Conservation 176, $490 \quad 191-198$.

Gurevitch, J., Koricheva, J., Nakagawa, S., Stewart, G., 2018. Meta-analysis and the science of 492 research synthesis. Nature 555, 175-182.

Haddad, N.M., Brudvig, L.A., Clobert, J., Davies, K.F., Gonzalez, A., al., e., 2015. Habitat

494 fragmentation and its lasting impact on Earth. Science Advances 1, e1500052.

Haddad, N.M., Gonzalez, A., Brudvig, L.A., Burt, M.A., Levey, D.J., Damschen, E.I., 2017.

496 Experimental evidence does not support the habitat amount hypothesis. Ecography 40, 48-55.

Hadley, A.S., Betts, M.G., 2016. Refocusing habitat fragmentation research using lessons from

498 the last decade. Current Landscape Ecology Reports 1, 55-66.

Hadley, A.S., Frey, S.J.K., Robinson, W.D., Kress, W.J., Betts, M.G., 2014. Tropical forest

500 fragmentation limits pollination of a keystone under story herb. Ecology 95, 2202-2212.

Haila, Y., 2002. A conceptual genealogy of fragmentation research: From island biogeography to

502 landscape ecology. Ecological Applications 12, 321-334.

Hanski, I., 2015. Habitat fragmentation and species richness. Journal of Biogeography 42, 989-

504993.

Hill, M.F., Caswell, H., 1999. Habitat fragmentation and extinction thresholds on fractal 506 landscapes. Ecology Letters 2, 121-127.

Hylander, K., Ehrlen, J., 2013. The mechanisms causing extinction debts. Trends in Ecology \& 508 Evolution 28, 341-346.

Jackson, S.T., Sax, D.F., 2010. Balancing biodiversity in a changing environment: extinction 510 debt, immigration credit and species turnover. Trends in Ecology \& Evolution 25, 153-160. 
Koper, N., Schmiegelow, F.K.A., Merrill, E.H., 2007. Residuals cannot distinguish between

512 ecological effects of habitat amount and fragmentation: implications for the debate. Landscape Ecology 22, 811-820.

514 Koricheva, J., Gurevitch, J., Mengersen, K., 2013. Handbook of meta-analysis in ecology and evolution. Princeton University Press.

516 Lasky, J.R., Keitt, T.H., 2013. Reserve Size and Fragmentation Alter Community Assembly, Diversity, and Dynamics. American Naturalist 182, E142-E160.

518 Laurance, W.F., Goosem, M., Laurance, S.G.W., 2009. Impacts of roads and linear clearings on tropical forests. Trends in Ecology \& Evolution 24, 659-669.

520 Laurance, W.F., Nascimento, H.E.M., Laurance, S.G., Andrade, A., Ribeiro, J.E.L.S., Giraldo, J.P., Lovejoy, T.E., Condit, R., Chave, J., Harms, K.E., D'Angelo, S., 2006. Rapid decay of tree522 community composition in Amazonian forest fragments. Proceedings of the National Academy of Sciences of the United States of America 103, 19010-19014.

524 Laurance, W.F., Useche, D.C., 2009. Environmental Synergisms and Extinctions of Tropical Species. Conservation Biology 23, 1427-1437.

526 Lindell, C.A., Riffell, S.K., Kaiser, S.A., Battin, A.L., Smith, M.L., Sisk, T.D., 2007. Edge responses of tropical and temperate birds. Wilson Journal of Ornithology 119, 205-220.

528 Liu, Z.F., He, C.Y., Wu, J.G., 2016. The Relationship between Habitat Loss and Fragmentation during Urbanization: An Empirical Evaluation from 16 World Cities. PLoS One 11.

530 Mac Nally, R., Lake, P.S., 1999. On the generation of diversity in archipelagos: a re-evaluation of the Quinn-Harrison 'saturation index'. Journal of Biogeography 26, 285-295.

532 MacArthur, R.H., Wilson, E.O., 1967. The theory of island biogeography. Princeton University Press, Princeton, NJ. 
Mitchell, M.G.E., Bennett, E.M., Gonzalez, A., 2014. Forest fragments modulate the provision of multiple ecosystem services. Journal of Applied Ecology 51, 909-918.

Newbold, T., Hudson, L.N., Hill, S.L.L., Contu, S., Lysenko, I., Senior, R.A., Borger, L.,

Bennett, D.J., Choimes, A., Collen, B., Day, J., De Palma, A., Diaz, S., Echeverria-Londono, S.,

Edgar, M.J., Feldman, A., Garon, M., Harrison, M.L.K., Alhusseini, T., Ingram, D.J., Itescu, Y.,

Kattge, J., Kemp, V., Kirkpatrick, L., Kleyer, M., Correia, D.L.P., Martin, C.D., Meiri, S.,

540 Novosolov, M., Pan, Y., Phillips, H.R.P., Purves, D.W., Robinson, A., Simpson, J., Tuck, S.L.,

Weiher, E., White, H.J., Ewers, R.M., Mace, G.M., Scharlemann, J.P.W., Purvis, A., 2015.

542 Global effects of land use on local terrestrial biodiversity. Nature 520, 45-+.

Pardini, R., Bueno, A.D., Gardner, T.A., Prado, P.I., Metzger, J.P., 2010. Beyond the

544 Fragmentation Threshold Hypothesis: Regime Shifts in Biodiversity Across Fragmented Landscapes. PLoS One 5.

546 Pfeifer, M., Lefebvre, V., Peres, C.A., Banks-Leite, C., Wearn, O.R., Marsh, C.J., Butchart, S.H.M., Arroyo-Rodríguez, V., Barlow, J., Cerezo, A., Cisneros, L., D’Cruze, N., Faria, D., 548 Hadley, A., Harris, S.M., Klingbeil, B.T., Kormann, U., Lens, L., Medina-Rangel, G.F., Morante-Filho, J.C., Olivier, P., Peters, S.L., Pidgeon, A., Ribeiro, D.B., Scherber, C., 550 Schneider-Maunoury, L., Struebig, M., Urbina-Cardona, N., Watling, J.I., Willig, M.R., Wood, E.M., Ewers, R.M., 2017. Creation of forest edges has a global impact on forest vertebrates.

$552 \quad$ Nature 551, 187.

Quiggen, J., 2010. Zombie economics: how dead ideas still walk among us. Princeton University 554 Press.

Quinn, J.F., Harrison, S.P., 1988. Effects of habitat fragmentation and isolation on species 556 richness: evidence from biogeographic patterns. Oecologia 75, 132-140. 
Radford, J.Q., Bennett, A.F., 2007. The relative importance of landscape properties for woodland 558 birds in agricultural environments. Journal of Applied Ecology 44, 737-747.

Ramsey, F.L., 1989. Comments on a saturation index. Oecologia 81, 569-570.

560 Ricketts, T.H., 2001. The matrix matters: Effective isolation in fragmented landscapes. American Naturalist 158, 87-99.

562 Ries, L., Fletcher, R.J., Battin, J., Sisk, T.D., 2004. Ecological responses to habitat edges: Mechanisms, models, and variability explained. Annual Review of Ecology Evolution and 564 Systematics 35, 491-522.

Ries, L., Murphy, S.M., Wimp, G.M., Fletcher, R.J., Jr., 2017. Closing persistent gaps in 566 knowledge about edge ecology. Current Landscape Ecology Reports 2, 30-41.

Rosch, V., Tscharntke, T., Scherber, C., Batary, P., 2015. Biodiversity conservation across taxa 568 and landscapes requires many small as well as single large habitat fragments. Oecologia 179, 209-222.

570 Ruffell, J., Banks-Leite, C., Didham, R.K., 2016. Accounting for the causal basis of collinearity when measuring the effects of habitat loss versus habitat fragmentation. Oikos 125, 117-125.

572 Rybicki, J., Hanski, I., 2013. Species-area relationships and extinctions caused by habitat loss and fragmentation. Ecology Letters 16, 27-38.

574 Schipper, J., Chanson, J.S., Chiozza, F., Cox, N.A., Hoffmann, M., Katariya, V., Lamoreux, J., Rodrigues, A.S.L., Stuart, S.N., Temple, H.J., Baillie, J., Boitani, L., Lacher, T.E., Mittermeier, 576 R.A., Smith, A.T., Absolon, D., Aguiar, J.M., Amori, G., Bakkour, N., Baldi, R., Berridge, R.J., Bielby, J., Black, P.A., Blanc, J.J., Brooks, T.M., Burton, J.A., Butynski, T.M., Catullo, G., 578 Chapman, R., Cokeliss, Z., Collen, B., Conroy, J., Cooke, J.G., da Fonseca, G.A.B., Derocher, A.E., Dublin, H.T., Duckworth, J.W., Emmons, L., Emslie, R.H., Festa-Bianchet, M., Foster, M., 
580 Foster, S., Garshelis, D.L., Gates, C., Gimenez-Dixon, M., Gonzalez, S., Gonzalez-Maya, J.F., Good, T.C., Hammerson, G., Hammond, P.S., Happold, D., Happold, M., Hare, J., Harris, R.B., 582 Hawkins, C.E., Haywood, M., Heaney, L.R., Hedges, S., Helgen, K.M., Hilton-Taylor, C., Hussain, S.A., Ishii, N., Jefferson, T.A., Jenkins, R.K.B., Johnston, C.H., Keith, M., Kingdon, J., 584 Knox, D.H., Kovacs, K.M., Langhammer, P., Leus, K., Lewison, R., Lichtenstein, G., Lowry, L.F., Macavoy, Z., Mace, G.M., Mallon, D.P., Masi, M., McKnight, M.W., Medellin, R.A., Medici, P., Mills, G., Moehlman, P.D., Molur, S., Mora, A., Nowell, K., Oates, J.F., Olech, W., Oliver, W.R.L., Oprea, M., Patterson, B.D., Perrin, W.F., Polidoro, B.A., Pollock, C., Powel, A., 588 Protas, Y., Racey, P., Ragle, J., Ramani, P., Rathbun, G., Reeves, R.R., Reilly, S.B., Reynolds, J.E., Rondinini, C., Rosell-Ambal, R.G., Rulli, M., Rylands, A.B., Savini, S., Schank, C.J., 590 Sechrest, W., Self-Sullivan, C., Shoemaker, A., Sillero-Zubiri, C., De Silva, N., Smith, D.E., Srinivasulu, C., Stephenson, P.J., van Strien, N., Talukdar, B.K., Taylor, B.L., Timmins, R., 592 Tirira, D.G., Tognelli, M.F., Tsytsulina, K., Veiga, L.M., Vie, J.C., Williamson, E.A., Wyatt, S.A., Xie, Y., Young, B.E., 2008. The status of the world's land and marine mammals: Diversity, 594 threat, and knowledge. Science 322, 225-230.

Smith, A.C., Fahrig, L., Francis, C.M., 2011. Landscape size affects the relative importance of 596 habitat amount, habitat fragmentation, and matrix quality on forest birds. Ecography 34, 103113.

598 Smith, A.C., Koper, N., Francis, C.M., Fahrig, L., 2009. Confronting collinearity: comparing methods for disentangling the effects of habitat loss and fragmentation. Landscape Ecology 24, $600 \quad 1271-1285$. 
Thompson, P.L., Rayfield, B., Gonzalez, A., 2017. Loss of habitat and connectivity erodes

602 species diversity, ecosystem functioning, and stability in metacommunity networks. Ecography 40, 98-108.

604 Tilman, D., Lehman, C.L., 1997. Habitat destruction and species extinctions, In Spatial ecology: the role of space in population dynamics and interspecific interactions. eds D. Tilman, P.

606 Kareiva. Princeton University Press, Princeton.

Tobler, W.R., 1970. Computer movie simulating urban growth in Detroit region. Economic

608 Geography 46, 234-240.

Tscharntke, T., Tylianakis, J.M., Rand, T.A., Didham, R.K., Fahrig, L., Batary, P., Bengtsson, J.,

610 Clough, Y., Crist, T.O., Dormann, C.F., Ewers, R.M., Frund, J., Holt, R.D., Holzschuh, A.,

Klein, A.M., Kleijn, D., Kremen, C., Landis, D.A., Laurance, W., Lindenmayer, D., Scherber,

612 C., Sodhi, N., Steffan-Dewenter, I., Thies, C., van der Putten, W.H., Westphal, C., 2012.

Landscape moderation of biodiversity patterns and processes - eight hypotheses. Biological

614 Reviews 87, 661-685.

Villard, M.A., Metzger, J.P., 2014. Beyond the fragmentation debate: a conceptual model to 616 predict when habitat configuration really matters. Journal of Applied Ecology 51, 309-318.

With, K.A., King, A.W., 2001. Analysis of landscape sources and sinks: the effect of spatial 618 pattern on avian demography. Biological Conservation 100, 75-88. 
Table 1. Major conclusions regarding 'zombie ideas' in Fahrig (2017), the evidence provided, and a non-exhaustive summary of counter evidence not considered in the review (focusing on meta-analyses, systematic reviews, and prior rebuttals).

\begin{tabular}{ll}
\hline $\begin{array}{l}\text { Fahrig's 'zombie } \\
\text { ideas' }\end{array}$ & Fahrig's evidence \\
\hline $\begin{array}{l}\text { Habitat } \\
\text { fragmentation has } \\
\text { widespread } \\
\text { negative effects }\end{array}$ & $\begin{array}{l}76 \% \text { of 'significant' } \\
\text { responses to habitat } \\
\text { fragmentation from } \\
\text { landscape studies were } \\
\text { positive. }\end{array}$ \\
& \\
$\begin{array}{l}\text { Small number of } \\
\text { large patches } \\
\text { contain more } \\
\text { species than large } \\
\text { number of small } \\
\text { patches }\end{array}$ & $\begin{array}{l}\text { SLOSS* analysis on species } \\
\text { richness: all 60 'significant' } \\
\text { (higher richness in many } \\
\text { small patches). }\end{array}$ \\
$\begin{array}{l}\text { Edge effects are } \\
\text { generally negative }\end{array}$ & $\begin{array}{l}\text { No data. Authors of papers } \\
\text { suggest that positive edge } \\
\text { effects may drive positive } \\
\text { responses to habitat } \\
\text { fragmentation. }\end{array}$ \\
&
\end{tabular}

Habitat
fragmentation
reduces
connectivity

Habitat specialists show greater negative responses

Negative habitat fragmentation responses are stronger at low levels of habitat amount

\section{Counter evidence not considered}

Haddad et al. (2015) provide a meta-analysis on long-term, patch-focused experiments for area, edge, and isolation, with edge and isolation effects controlling for habitat area and habitat heterogeneity. Effects are consistently negative (80\% isolation; $82 \%$ edge) and increasingly so over time, emphasizing limitations of space-for-time substitution.

Ramsey (1989) and Mac Nally and Lake (1999) argue that this type of SLOSS analysis is flawed, yielding biased results (in the direction shown by Fahrig), and that it does not provide a means of assessing 'significance'.

Ries et al. (2004), Fletcher et al. (2007), and Pfeifer et al. (2017) show variable edge effects. Pfeifer et al. (2017) meta-analysis shows that species with negative edge effects are 3.7 times more likely to be of conservation concern (IUCN threatened), while positive responses include pest/invasive species.

Meta-analysis on corridor effects shows positive effect of corridors (less fragmented), with $50 \%$ increase in movement ( $n=28$ studies) along corridors when controlling for habitat area (Gilbert-Norton et al. 2010).

Pfeifer et al. (2017) meta-analysis shows that negative edge effects are typically observed for specialist species, positive for generalist species. 'endangered/threatened/spec ialist': 29 of 30 significant responses to habitat fragmentation were positive.

Proportion of negative responses to habitat fragmentation were similar when comparing $<0.2(31 \%)$ habitat to $>0.2(33 \%)$.
Theory emphasizes that specific thresholds are contingent on assumptions regarding movement (e.g., patch-delineation rules; Swift and Hannon 2010)(Hanski 2015; With and King 2001). Fahrig's results do not support this claim when considered a larger threshold : $<0.5$ (33.3\% negative) versus > 0.5 ( $8 \%$ negative). 
Negative fragmentation responses are stronger in the tropics
Proportion positive responses similar for 'subtropical/tropical' versus other.
Lindell et al. (2007) meta-analysis shows that tropical birds are more likely to avoid edges than temperate birds.

*SLOSS analyses based on species accumulation curves. Only the lack of crossing accumulation curves was taken as 'significant', although Mac Nally and Lake (1999) show this conclusion provides no statistical inference on 'significance'. 